\title{
Effects of FUdR on gene expression in the $C$. elegans bacterial diet OP50
}

\author{
Grace McIntyre ${ }^{1}$, Justin Wright ${ }^{2}$, Hoi Tong Wong ${ }^{2}$, Regina Lamendella ${ }^{2}$ and Jason Chan ${ }^{1 *}$ (D)
}

\begin{abstract}
Objective: Many C. elegans aging studies use the compound 5-fluro-2'-deoxyuridine (FUdR) to produce a synchronous population of worms. However, the effects of FUdR on the bacterial gene expression of OP50 E. coli, the primary laboratory C. elegans food source, is not fully understood. This is particularly relevant as studies suggest that intestinal microbes can affect $C$. elegans physiology. Therefore, it is imperative that we understand how exposure to FUdR can affect gene expression changes in OP50 E. coli.

Results: An RNAseq dataset comprised of expression patterns of 2900 E. coli genes in the strain OP50, which were seeded on either nematode growth media (NGM) plates or on FUdR (50 $\mu$ M) supplemented NGM plates, was analyzed. Analysis showed differential gene expression in genes involved in general transport, amino acid biosynthesis, transcription, iron transport, and antibiotic resistance. We specifically highlight metabolic enzymes in the L-histidine biosynthesis pathway as differentially expressed between NGM and FUdR exposed OP50. We conclude that OP50 exposed to FUdR results in differential expression of many genes, including those in amino acid biosynthetic pathways.
\end{abstract}

Keywords: C. elegans, E. coli, FUdR, Aging, Bacterial transcriptomics

\section{Introduction}

Many C. elegans aging studies use the compound 5-fluro2'-deoxyuridine (FUdR) to produce a synchronous population of worms. FUdR is often added directly to nematode growth media (NGM) agar plates to prevent egg hatching by inhibiting DNA synthesis $[1,2]$. However, the effects of FUdR on the bacterial gene expression of OP50 E. coli, the primary laboratory C. elegans food source, is not fully understood. This is particularly relevant as studies suggest that intestinal microbes can affect host physiology [3-5]. Indeed, bacterial metabolites such as colanic acid extend host lifespan whereas folic acid reduces lifespan [6, 7]. E. coli is also known to produce compounds affecting host neuronal function

*Correspondence: jchan@marian.edu

1 Department of Biology, Marian University, 3200 Cold Spring Rd, Indianapolis, IN 46222, USA

Full list of author information is available at the end of the article including GABA and lactate which contribute to neuroprotection [8]. While bacterial metabolites are essential to host nutrition and physiology in worms, bacterial load accumulates as the host ages leading to death and a reduced lifespan [9]. Recently, it has also been shown that E. coli's metabolic conversion of FUdR to 5-fluorouridine monophosphate (FUMP) can impair C. elegans fecundity and highlight the role of bacteria in host health [10-12]. Moreover, FUdR may directly affect $C$. elegans hosts by improving thermal stress response, protein homeostasis, and altering lifespan in some mutant backgrounds $[6$, 13-15]. Thus, further studies analyzing the gene expression changes in OP50 E. coli exposed to FUdR may provide insight into aging and other studies.

\section{Main text}

To assess the role of FUdR on bacterial gene expression changes, we analyzed a dataset of gene expression differences between OP50 E. coli seeded on NGM agar

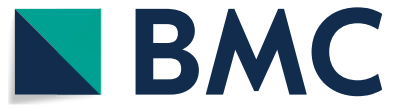

(c) The Author(s) 2021. This article is licensed under a Creative Commons Attribution 4.0 International License, which permits use, sharing, adaptation, distribution and reproduction in any medium or format, as long as you give appropriate credit to the original author(s) and the source, provide a link to the Creative Commons licence, and indicate if changes were made. The images or other third party material in this article are included in the article's Creative Commons licence, unless indicated otherwise in a credit line to the material. If material is not included in the article's Creative Commons licence and your intended use is not permitted by statutory regulation or exceeds the permitted use, you will need to obtain permission directly from the copyright holder. To view a copy of this licence, visit http://creativeco mmons.org/licenses/by/4.0/. The Creative Commons Public Domain Dedication waiver (http://creativecommons.org/publicdomain/ zero/1.0/) applies to the data made available in this article, unless otherwise stated in a credit line to the data. 
plates and on NGM plates supplemented with $50 \mu \mathrm{M}$ FUdR (NGM + FUdR). This analysis was part of a previous study examining how bacterial gene expression changed in different genetic models of aging, including the longer-lived $d a f$-2/insulin-like growth factor receptor and shorter-lived daf-16/FOXO transcription factor mutants [16]. The RNAseq data comprised of $2900 \mathrm{E}$. coli genes; $Q$ scores of reads were determined by FastQC and filtered for reads at a 4-base average $Q$ score of 20 or lower using Trimmomatic, as previously described [17]. The raw gene counts (per million) were transformed into a $\log _{2}$ scale and cleared of low-quality reads by removing $25 \%$ of the probes with the weakest signal. We then identified the top 158 genes with an interquartile range (IQR) > 1.5 (Additional file 1: Table S1). We identified the biological functions of these genes and found genes that are involved in amino acid biosynthesis (32), general transport (28), stress response (13), transcription (12), DNA repair (7), iron transport (6), DNA damage (5), and antibiotic resistance (4). We surmise that some of these genes may be regulated in direct response to FUdR's effect on DNA.
We further limited our list by examining genes with an IQR $>2.5$, which resulted in 28 genes with the greatest differential gene expression (Fig. 1 and Table 1). Hierarchical clustering showed that bacteria from NGM only plates clustered most closely with other NGM only plates, and away from bacteria exposed to FUdR. We found that several of these differentially expressed genes (DEG), including hisA, hisB, hisC, hisD, hisG, and hisI, belong to the L-histidine biosynthesis pathway (Fig. 2). Each of these genes are upregulated in E. coli treated with FUdR compared to NGM only. These genes operate under an operon, suggesting that histidine production is increased by FUdR. Histidine can impact cell functions such as energy metabolism and growth, and is necessary in many enzymes as a proton acceptor or donor [18]. Indeed, targeting L-histidine metabolism enzymes may be a therapeutic target to limit survival of Myobacterium tuberculosis and other bacteria, suggesting a critical role for histidine in bacterial survival $[19,20]$. Previous reports in bacteria also show that histidine starvation can induce metabolomic changes in E. coli and that histidine dehydrogenase (hisD) is important for bacterial

\section{Differential E. coli Genes Expressed When Exposed to FUdR}

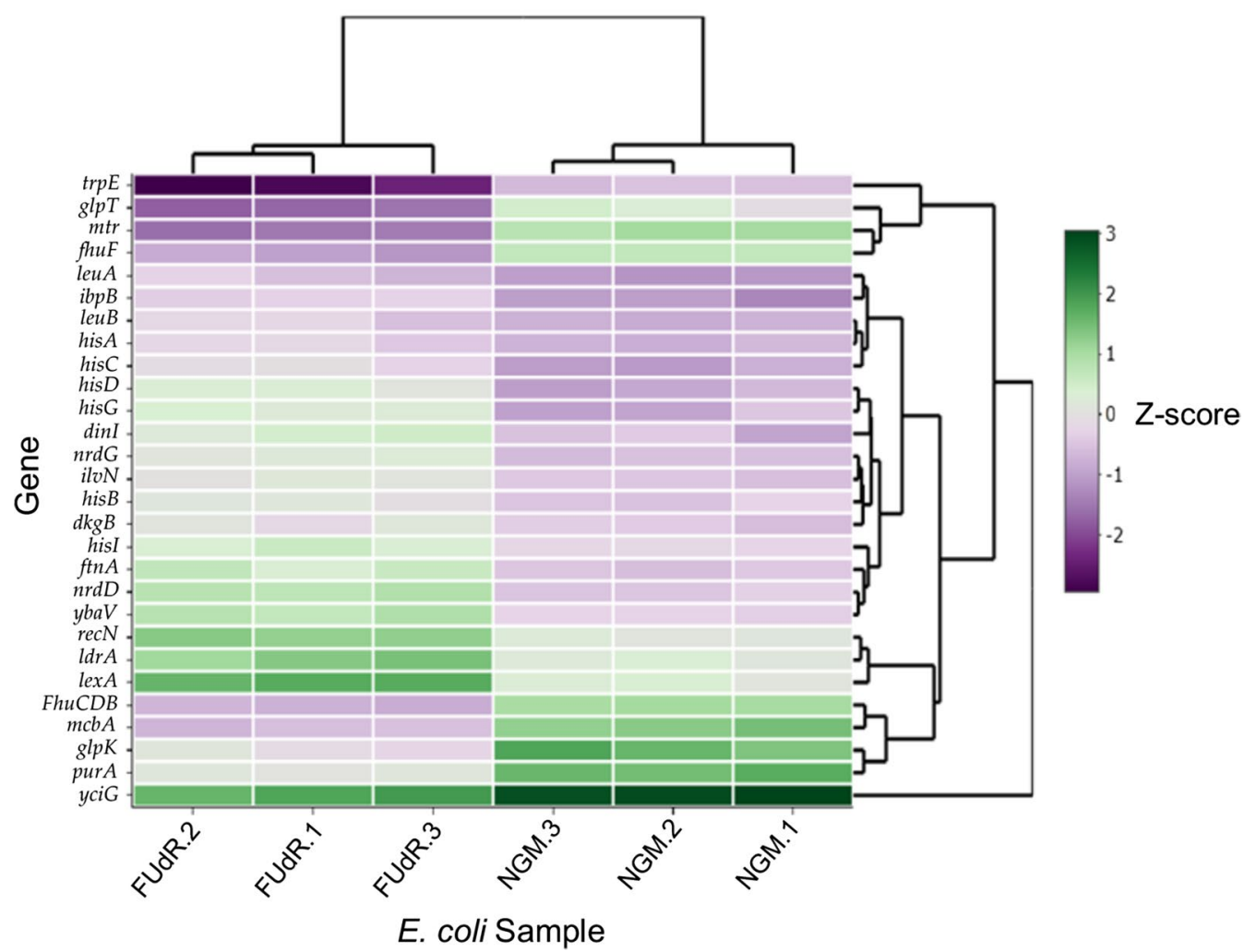

Fig. 1 Differentially expressed OP50 E. coli genes in response to FUdR. Heatmap demonstrating the top 28 differentially expressed genes in E. coli (in triplicate) grown on either NGM only (NGM.1-3) or NGM plates supplemented with $50 \mu$ M FudR (FudR.1-3) 
Table 1 Top differentially expressed genes when exposed to $50 \mu \mathrm{M}$ FUdR

\begin{tabular}{|c|c|c|c|c|c|}
\hline Protein & Gene & LogFC & P-Value & FDR & Function \\
\hline \multicolumn{6}{|l|}{ Amino acid metabolism } \\
\hline $\begin{array}{l}\text { Phosphoribosylformimino } 5 \text {-aminoimidazole } \\
\text { carboxamide ribotide isomerase }\end{array}$ & hisA & 2.83 & $6.29 E-23$ & $6.02 E-21$ & L-Histidine biosynthesis \\
\hline $\begin{array}{l}\text { Imidazoleglycerol phosphate dehydrogenase/histi- } \\
\text { dinol phosphate }\end{array}$ & hisB & 2.71 & $3.04 \mathrm{E}-21$ & $2.38 \mathrm{E}-19$ & L-Histidine biosynthesis pathway \\
\hline Histidinol-phosphate aminotransferase & hisC & 3.7 & $9.40 E-31$ & $2.21 \mathrm{E}-28$ & L-Histidine biosynthesis pathway \\
\hline Histidinol dehydrogenase & hidD & 4.19 & $1.31 \mathrm{E}-34$ & $3.37 \mathrm{E}-32$ & L-Histidine biosynthesis pathway \\
\hline ATP phosphotibosyltransferase & hisG & 4.04 & $9.69 \mathrm{E}-28$ & $1.56 \mathrm{E}-25$ & L-Histidine biosynthesis pathway \\
\hline $\begin{array}{l}\text { Phosphoribosyl atp pyrophosphohydrolase/phos- } \\
\text { phoribosyl amp cyclohydrolase }\end{array}$ & hisl & 2.94 & $2.00 E-24$ & $2.24 \mathrm{E}-22$ & L-Histidine biosynthesis pathway \\
\hline Acetolactate synthase I/III small subunit & $i / v N$ & 2.93 & $7.50 E-30$ & $1.29 E-27$ & $\begin{array}{l}\text { Amino acid biosynthesis, pyruvate fermentation to } \\
\text { isobutanol, L-valine biosynthesis }\end{array}$ \\
\hline 2-Isopropylmalate synthase & leuA & 3.26 & $1.22 \mathrm{E}-23$ & $1.26 \mathrm{E}-21$ & $\begin{array}{l}\text { 3-methylbutanol biosynthesis Pathway, L-leucine } \\
\text { biosynthesis }\end{array}$ \\
\hline 3-Isopropylmalate dehydrogenase & leuB & 2.91 & $6.79 \mathrm{E}-21$ & $5.01 \mathrm{E}-19$ & $\begin{array}{l}\text { 3-methylbutanol biosynthesis pathway, L-leucine } \\
\text { biosynthesis }\end{array}$ \\
\hline Tryptophan specific transport protein & $m t r$ & -4.57 & $2.69 E-48$ & $1.74 \mathrm{E}-45$ & $\begin{array}{l}\text { Aromatic amino acid transmembrane transporter } \\
\text { activity }\end{array}$ \\
\hline Anthranilate synthase component 1 & $\operatorname{trp} E$ & -2.87 & $2.81 \mathrm{E}-24$ & $3.02 \mathrm{E}-22$ & Amino acid biosynthesis, L-tryptophan biosynthesis \\
\hline \multicolumn{6}{|l|}{ DNA replication, binding, and repair } \\
\hline Bacteriocin microcin b17 & $m c b A$ & -3.54 & $1.08 \mathrm{E}-39$ & $3.10 \mathrm{E}-37$ & DNA replication inhibitor, Antibiotic \\
\hline Repressor lexA & lexA & 4.37 & $2.24 \mathrm{E}-38$ & $1.54 \mathrm{E}-35$ & $\begin{array}{l}\text { DNA damage, DNA repair, DNA replication, transcrip- } \\
\text { tion, transcription regulation }\end{array}$ \\
\hline DNA repair protein recN & $\operatorname{rec} N$ & 3.7 & $4.30 \mathrm{E}-40$ & $1.39 \mathrm{E}-37$ & DNA damage, DNA repair \\
\hline Competence protein comea & ybaV & 3.97 & $4.98 \mathrm{E}-50$ & $4.29 \mathrm{E}-47$ & DNA binding \\
\hline \multicolumn{6}{|l|}{ Ion transport and signaling } \\
\hline High affinity iron transporter & FhuCDB & -3.03 & $1.16 \mathrm{E}-27$ & $1.76 \mathrm{E}-25$ & Ion transport \\
\hline Ferric iron reductase protein & fhuF & -2.56 & $8.41 \mathrm{E}-20$ & $5.71 \mathrm{E}-18$ & Colonic acid biosynthesis process \\
\hline Bacteria non-heme ferritin 1 & $\operatorname{tn} A$ & 3.96 & $7.42 \mathrm{E}-42$ & $3.83 \mathrm{E}-39$ & Iron storage \\
\hline Ribonucleoside triphosphate reductase & $\operatorname{nrdD}$ & 4.3 & $6.53 \mathrm{E}-54$ & $1.69 E-50$ & $\begin{array}{l}\text { Reduces thioredoxin, ATP binding, Zinc ion binding, } \\
\text { Nucleotide binding }\end{array}$ \\
\hline $\begin{array}{l}\text { Anaerobic ribonucleoside triphosphate reductase } \\
\text { activating protein }\end{array}$ & $n r d G$ & 3.37 & $7.01 \mathrm{E}-41$ & $3.02 E-38$ & Metal ion binding, catalyzes 5'-deoxy-adenosine \\
\hline \multicolumn{6}{|l|}{ Other } \\
\hline DNA damage inducible protein 1 & $\operatorname{dinl}$ & 3.86 & $3.28 \mathrm{E}-30$ & $6.24 \mathrm{E}-28$ & Reductive ion assimilation \\
\hline 2,5-diketo-D-gluconate reductase b & $d \mathrm{~kg} B$ & 2.64 & $2.24 \mathrm{E}-25$ & $2.75 \mathrm{E}-23$ & Ascorbate biosynthesis \\
\hline Glycerol kinase & glpk & -3.27 & $1.32 \mathrm{E}-15$ & $5.01 \mathrm{E}-14$ & Glycerol degradation 1 pathway \\
\hline $\begin{array}{l}\text { mfs transporter, opa family, glycerol } 3 \text { phosphate } \\
\text { transporter }\end{array}$ & glpT & -3.02 & $1.15 E-17$ & $5.28 \mathrm{E}-16$ & Glycerol metabolism, Transport \\
\hline $\begin{array}{l}\text { Small heat shock protein, molecular chaperone } \\
\text { ibpB }\end{array}$ & $i b p B$ & 3.71 & $6.52 \mathrm{E}-52$ & $8.41 \mathrm{E}-49$ & Stress response \\
\hline Small toxic polypeptide & $I d r A$ & 3.58 & $2.55 \mathrm{E}-30$ & $5.48 \mathrm{E}-28$ & Toxin-antitoxin system \\
\hline $\begin{array}{l}\text { Anaerobic ribonucleoside triphosphate reductase } \\
\text { activating protein }\end{array}$ & $\operatorname{nrdG}$ & 3.37 & $7.01 \mathrm{E}-41$ & $3.02 E-38$ & Metal ion binding, catalyzes 5'-deoxy-adenosine \\
\hline Adenylosuccinate synthase & purA & -2.75 & $1.30 E-27$ & 1.87E-25 & Adenosine ribonucleotides de novo biosynthesis \\
\hline Uncharacterized protein yciG & yciG & -2.81 & $5.15 \mathrm{E}-19$ & $3.17 \mathrm{E}-17$ & Bacterial type flagellum dependent swarming motility \\
\hline
\end{tabular}

A table describing the general biological function of the top 28 differentially expressed genes in $E$. coli with statistically significant $(P<0.0001)$ log fold changes

survival against pathogens $[18,21,22]$. Interestingly, histidine is an essential amino acid for worms and can lead to moderate increases in C. elegans' mean lifespan, of gst4 and $n h r-57$ expression, and resistance to heavy metal toxicity $[23,24]$. Given that dietary histidine can have a wide range of benefits for humans, including reduction of inflammation, blood pressure, and metabolic syndrome, our findings may highlight the importance 


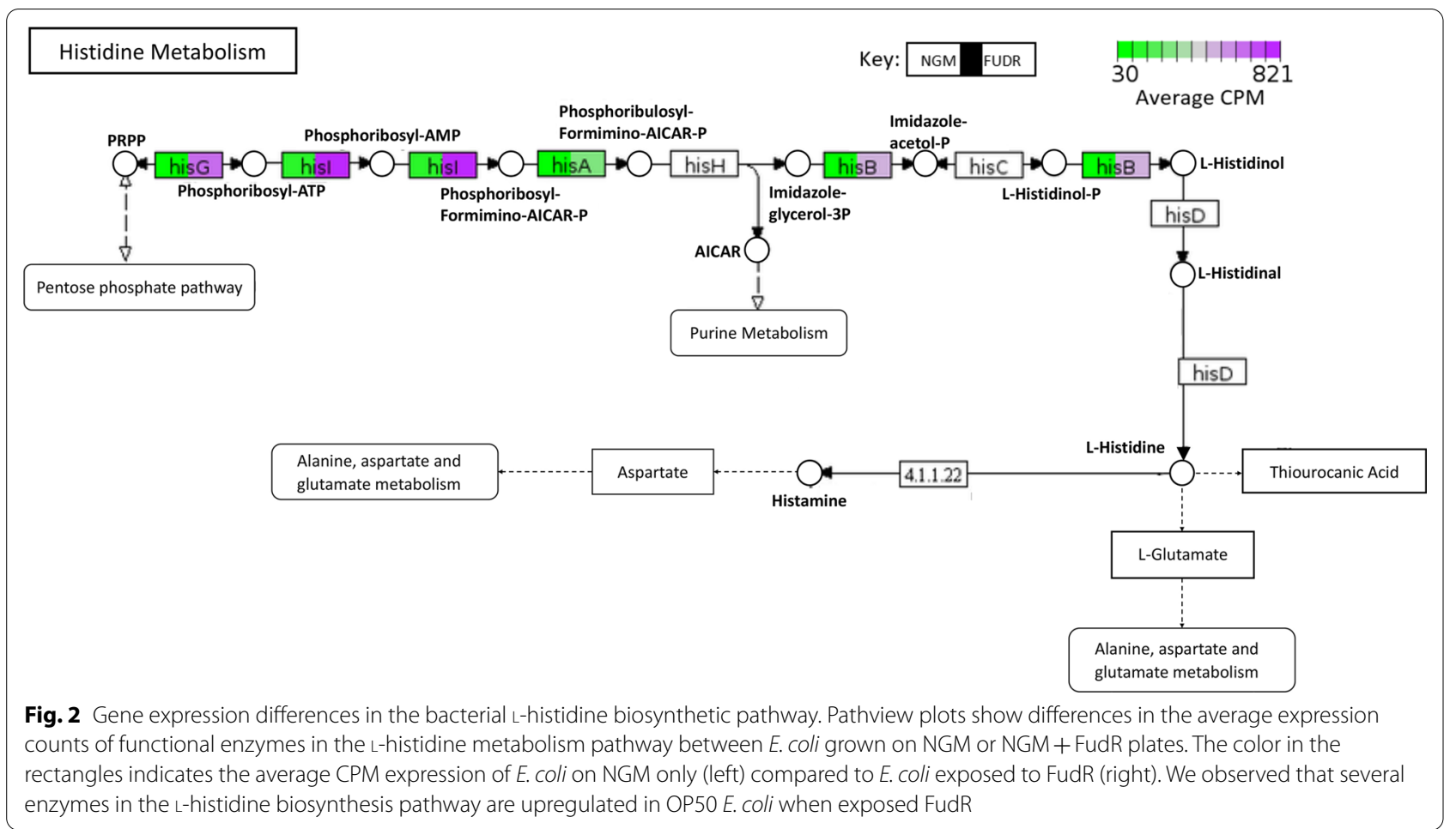

of understanding histidine metabolism in host-bacterial interactions [19].

We also found that FUdR downregulated genes affecting the amino acid tryptophan in OP50 E. coli, including the metabolic enzyme antthranilate synthase, $\operatorname{trpE}$ (2.87-fold decrease, $P=2.81 \times 10^{-24}$ ), and the tryptophan specific transport protein gene, $m$ tr (4.56-fold decrease, $\left.P=5.44 \times 10^{-46}\right)$. It is unknown whether FUdR affects tryptophan levels in this study, but decreased $\operatorname{trpE}$ expression may be indicative of elevated L-tryptophan. $\operatorname{trp} E$ acts as an early step of L-tryptophan biosynthesis and is susceptible to feedback regulation by L-tryptophan [25]. Previous work demonstrated that an increased abundance of tryptophan is associated with increased lifespan in C. elegans and microbial tryptophan may serve pro-immune functions in other hosts $[26,27]$. However, others show that tryptophan can cause toxicity in worms independent of FUdR, and that pathogenic $E$. coli use tryptophan to produce a secreted toxin that kills hosts [11, 28]. Furthermore, knockout of the transporter $m t r$ has been shown to reduce tryptophan intake in $E$. coli, but increase internal $\mathrm{L}$-tryptophan production [29]. Thus, our observations support that FUdR increases L-tryptophan production, and may be part of the mechanism that diminishes $C$. elegans health.

Our analysis also revealed that the iron storage ferritin protein gene, $f \operatorname{tn} A$ is significantly upregulated by FUdR (3.96-fold increase, $P=7.42 \times 10^{-42}$ ). Furthermore,
fhuF and $f h u C D B$, which are downregulated by FUdR, are components of ferri-siderophore transport of iron in bacterial membranes. Iron homeostasis is critical for bacteria and other organisms, but it is unclear how FUdR affects iron balance [30]. A lack of intestinal and pharyngeal ferritin in ftn-1 C. elegans mutants results in reduced longevity [31]. Importantly, it is not known whether gene expression changes in bacteria ultimately alter bacterial tryptophan or iron abundance. Further studies are needed to specifically address the impact of $E$. coli's L-histidine biosynthesis enzymes, $m$ tr and trpE expression, $f \operatorname{tn} A$ expression, and other differentially expressed genes and the effects FUdR on C. elegans physiology and lifespan.

Work examining bacterial metabolism in worms has identified that E. coli and Comamonas can metabolize FUdR and impact host physiology [10, 11]. Garcia-Gonzalez et al. [10] found that bacteria can either metabolize FUdR to produce fluorouridine monophosphate (FUMP) and affect ribonucleotide metabolism, or to be part of DNA metabolism via FdUMP. FUMP can be synthesized by direct conversion of FUdR into 5-fluorouracil (5-FU) by deoA (thymidine phosphoarylase) and conversion of 5-FU into FUMP by upp (uracil phosphoribosyltransferase). Interestingly, in our analysis, FUdR treated OP50 resulted in increased expression of both $\operatorname{deo} A$ (twofold; $P=0.7 .52 \times 10^{-6}$ ) and $u p p$ (twofold, $P=2.3 \times 10^{-4}$ ) (Additional file 2: Figure S1). 
Furthermore, Ke et al. [11] showed that knockout of thymidine kinase $(t d k)$, which directly converts FUdR to FdUMP, enhances the detrimental effects of FUdR. We did not find changes in expression of $t d k$ or other downstream enzymes leading to thymidine (dTTP) synthesis (Additional file 2: Figure S1), suggesting that FUdR treated E. coli may be driven toward FUMP, not FdUMP production.

Bacteria in C. elegans have also been shown to metabolize folate to produce 5-methyl-tetrahydrofolate (5-meTHF), which then impacts methionine metabolism and lifespan in worms [32]. L-Serine to glycine interconversion can produce 5,10-methylene-tetrahydrofolate (5,10-meTHF), a precursor of 5-meTHF, through the enzyme glyA. We did not observe changes in gene expression in $g l y A$, but we did observe increased gene expression of two L-serine metabolism enzymes, serA (3.3-fold increase, $\left.P=6.73 \times 10^{-15}\right)$ and $\operatorname{ser} C(1.85$ fold increase, $P=6.45 \times 10^{-4}$ ) but not of ser $B$, which directly synthesizes L-serine (Additional file 2: Figure S1). Thus, it is possible that the substrates necessary to produce 5-meTHF are elevated by FUdR. Furthermore, we did not observe changes in gene expression in thymidylate synthase (thyA), which uses 5,10-meTHF convert dUMP to dTMP. Further exploration is necessary to determine the effects of FudR alone on tetrahydrofolate biosynthesis.

Finally, to determine how gene responses to FUdR identified in this study compare to bacterial responses to other factors, we compared our gene list to those previously analyzed. First, our previous report identified a list of core genes in E. coli of 4-day-old C. elegans hosts. When comparing this to the 158 genes identified in this study, very few overlapped (5/158), suggesting that FUdR initiated a stress specific response. Our previous study also identified differentially expressed bacterial genes in $C$. elegans in various conditions, including temperature and host genotype. We compared those DEGs with genes that were differentially expressed in this study and found 23 common genes regulated by temperature $\left(15{ }^{\circ} \mathrm{C}\right.$ compared to $\left.20{ }^{\circ} \mathrm{C}\right)$, 9 by $d a f-2 /$ InsR mutations, and 17 by daf-16/FOXO mutations overlapped with our 158 genes (Additional file 3: Table S2). There were very few overlapping DEGs, which may be expected given that our study examined change in bacteria in vitro, and those conditions were in vivo. When comparing our dataset to transcriptomics analysis of E. coli exposed to volatile organic compounds, some common pathways regulated iron related gene regulation, including $f h u F$, and leucine biosynthesis [33]. Similarly, E. coli treated with the antibiotics potentiator bicarbonate led to increased expression of genes regulating tryptophan and iron, including those in the $f h u$ operon [34]. Thus, amino acid and iron regulation may be common responses to chemical treatments, including FUdR.

\section{Conclusion}

In conclusion, these results highlight several genes regulated in OP50 E. coli in the presence of FudR. As bacterial diets affect $C$. elegans physiology and longevity, a greater understanding of metabolic networks in bacteria would provide insight to host-microbe interactions. Though this study identifies specific changes in E. coli biosynthesis genes and pathways in response to FudR, and further testing of metabolite changes and its impact on host physiology are needed.

\section{Methods}

Sample collection, RNA preparation, sequencing, and gene counts (counts per million) were collected as previously described [16]. Briefly, OP50 Escherichia coli (E. coli), a standard diet use for laboratory C. elegans, was seeded on nematode growth media (NGM) or NGM $+50 \mu \mathrm{M}$ FudR agar plates. Bacteria were harvested from 3 experimental replicates (3 independent plates from 1 experiment) and prepared for transcriptomics analysis. Genes that mapped to E. coli were used for downstream analyses, and gene expression was compared in OP50 bacteria seeded NGM and $\mathrm{NGM}+$ FudR $(50 \mu \mathrm{M})$ agar plates.

\section{Pathview analysis}

Average normalized CPM counts of identified L-Histidine biosynthesis enzymes were selected using Entrez Reference Sequence identification numbers and mapped to the E. coli Histidine Metabolism Pathway (EC00340) using the R package pathview on PathviewWeb [35-40]. Histidine metabolism pathway was simplified with focus on the L-Histidine biosynthesis pathway.

\section{Heatmap and genetic analysis}

Genes with an IQR $>1.5$ produced 158 differentially expressed genes (DEG); (Additional file 1: Table S1). Ninety-two of those DEG were classified based on enzyme parent class and molecular function using EcoCyc and Uniprot databases [41, 42]. Gene counts with an IQR $>2.5$ produced 28 DEG which had the greatest expression differences in the presence of FudR based on FDR, $\operatorname{logFC}$, and $P$-value; this analysis was conducted in $\mathrm{R}$ 4.0.0 using the package edge $\mathrm{R}$ and heatmaply [43-48]. Gene name, biological pathway, and protein function was determined using MetaCyc, EcoCyc, and Uniprot databases. [41, 42, 49]. 


\section{Reagents}

Bacteria Strain-Escherichia coli strain OP50 provided by CGC (NIH Office of Research Infrastructure Programs (P40 OD010440).

\section{Limitations}

Our analysis of FudR on OP50 E. coli's gene expression has identified gene expression differences caused by the presence of FudR. However, this analysis has only identified patterns in gene expression differences. To assess the mechanistic role of FudR on these pathways and downstream metabolites, further studies examining enzymatic changes in E. coli's metabolism and its effect on host physiology are needed.

In addition to OP50, other E. coli strains including HB101 and HT115 are used as a C. elegans food source in lab settings. Furthermore, in the wild, C. elegans has been known to feed on a wide variety of bacteria including Pseudomonas, Ochrobactrum, Methylobacterium, Xanthomonas, and Sphingomonas [50-53]. As FudR is commonly used in combination with alterations in bacterial diets, further studies investigating the role of FudR in other bacterial strains may provide greater insight into the roles of bacterial metabolites on C. elegans.

\section{Supplementary Information}

The online version contains supplementary material available at https://doi. org/10.1186/s13104-021-05624-6.

Additional file 1: Table S1. The top 158 differentially expressed genes in OP50 E. coli exposed to FUdR.

Additional file 2: Figure S1. Gene expression differences of biosynthetic pathways for FUdR metabolism. Top, FUdR can be metabolized into FUMP or FdUMP. Expression of deoA and upp are increased (red arrows) in FUdR treated $E$. coli, whereas other metabolic enzmes do not show differential gene expression. (top) and 5,10-meTHF (bottom). Bottom, Serine can be metabolized to produce 5,10-meTHF. The expression of I-serine biosynthetic enzymes serA and serC increase in FUdR treated $E$. coli, but expression of enzymes directly snythesizing 5,10-meTHF from I-serine are not changed.

Additional file 3: Table S2. Common bacterial genes in OP50 E. coli regulated in response to FUdR and in specific hosts.

\section{Acknowledgements}

We would like to acknowledge Marian University's College of Arts and Sciences and Juniata College for their support of this work.

\section{Authors' contributions}

GM carried out experimental analysis and helped draft the manuscript. JC conceived the study and participated in its design. JC, JW, HTW, and RL participated in the design and investigation of the study. RL and JC carried out the initial conceptualization for the experiment and was responsible for the funding acquisition for this research. JC also participated in the formal analysis and coordinated and drafted the manuscript. All authors read and approved the final manuscript.

\section{Funding}

Research reported in this publication was supported by the National Institute On Aging of the National Institutes of Health under Award Number R15AG052933 (JC) and R15AG063103 (RL). The content is solely the responsibility of the authors and does not necessarily represent the official views of the National Institutes of Health.

\section{Availability of data and materials}

The datasets analyzed during the current study are available from the corresponding author on reasonable request. The datasets used during this study are included in this published article and its additional information files.

\section{Declarations}

Ethics approval and consent to participate

Not applicable.

\section{Consent for publication}

All authors have consented to the publication of this work.

\section{Competing interests}

We the authors declare that there is no conflict of interest concerning this research.

\section{Author details}

${ }^{1}$ Department of Biology, Marian University, 3200 Cold Spring Rd, Indianapolis, IN 46222, USA. ²Department of Biology, Juniata College, 1700 Moore St, Huntingdon, PA 16652, USA.

Received: 26 December 2020 Accepted: 19 May 2021

Published online: 28 May 2021

\section{References}

1. Mitchell DH, Stiles JW, Santelli J, Sanadi DR. Synchronous growth and aging of Caenorhabditis elegans in the presence of fluorodeoxyuridine. J Gerontol. 1979;34(1):28-36.

2. Gandhi S, Santelli J, Mitchell DH, Stiles JW, Sanadi DR. A simple method for maintaining large, aging populations of Caenorhabditis elegans. Mech Ageing Dev. 1980;12(2):137-50.

3. Lenaerts I, Walker GA, Van Hoorebeke L, Gems D, Vanfleteren JR. Dietary restriction of Caenorhabditis elegans by axenic culture reflects nutritional requirement for constituents provided by metabolically active microbes. J Gerontol A Biol Sci Med Sci. 2008;63(3):242-52.

4. Neve IAA, Sowa JN, Lin CJ, Sivaramakrishnan P, Herman C, Ye Y, et al. Metabolite profiling leads to the development of an RNA interference strain for. G3 (Bethesda). 2020;10(1):189-98.

5. Kumar A, Baruah A, Tomioka M, lino Y, Kalita MC, Khan M. Caenorhabditis elegans: a model to understand host-microbe interactions. Cell Mol Life Sci. 2020:77(7):1229-49.

6. Virk B, Correia G, Dixon DP, Feyst I, Jia J, Oberleitner N, et al. Excessive folate synthesis limits lifespan in the C. elegans: E. coli aging model. BMC Biol. 2012;10:67

7. Cabreiro F Gems D. Worms need microbes too: microbiota, health and aging in Caenorhabditis elegans. EMBO Mol Med. 2013;5(9):1300-10.

8. Urrutia A, García-Angulo VA, Fuentes A, Caneo M, Legüe M, Urquiza S, et al. Bacterially produced metabolites protect C. elegans neurons from degeneration. PLoS Biol. 2020;18(3):e3000638.

9. Portal-Celhay C, Blaser MJ. Competition and resilience between founder and introduced bacteria in the Caenorhabditis elegans gut. Infect Immun 2012:80(3):1288-99.

10. García-González AP, Ritter AD, Shrestha S, Andersen EC, Yilmaz LS, Walhout AJM. Bacterial metabolism affects the C. elegans response to cancer chemotherapeutics. Cell. 2017;169(3):431-41.e8.

11. Ke W, Saba JA, Yao CH, Hilzendeger MA, Drangowska-Way A, Joshi C, et al. Dietary serine-microbiota interaction enhances chemotherapeutic toxicity without altering drug conversion. Nat Commun. 2020;11(1):2587. 
12. Scott TA, Quintaneiro LM, Norvaisas P, Lui PP, Wilson MP, Leung KY, et al. Host-microbe co-metabolism dictates cancer drug efficacy in C. elegans. Cell. 2017;169(3):442-56.e18.

13. Feldman N, Kosolapov L, Ben-Zvi A. Fluorodeoxyuridine improves Caenorhabditis elegans proteostasis independent of reproduction onset. PLoS ONE. 2014;9(1):e85964.

14. Angeli S, Klang I, Sivapatham R, Mark K, Zucker D, Bhaumik D, et al. A DNA synthesis inhibitor is protective against proteotoxic stressors via modulation of fertility pathways in Caenorhabditis elegans. Aging (Albany NY) 2013;5(10):759-69.

15. Anderson EN, Corkins ME, Li JC, Singh K, Parsons S, Tucey TM, et al. C. elegans lifespan extension by osmotic stress requires FUdR, base excision repair, FOXO, and sirtuins. Mech Ageing Dev. 2016;154:30-42.

16. Chan JP, Wright JR, Wong HT, Ardasheva A, Brumbaugh J, McLimans C, et al. Using bacterial transcriptomics to investigate targets of host-bacterial interactions in Caenorhabditis elegans. Sci Rep. 2019;9(1):5545.

17. Bolger AM, Lohse M, Usadel B. Trimmomatic: a flexible trimmer for Illumina sequence data. Bioinformatics. 2014;30(15):2114-20.

18. Winkler ME, Ramos-Montañez S. Biosynthesis of histidine. EcoSal Plus. 2009. https://doi.org/10.1128/ecosalplus.3.6.1.9.

19. Monti SM, De Simone G, D'Ambrosio K. L-Histidinol dehydrogenase as a new target for old diseases. Curr Top Med Chem. 2016;16(21):2369-78.

20. Lunardi J, Nunes JE, Bizarro CV, Basso LA, Santos DS, Machado P. Targeting the histidine pathway in Mycobacterium tuberculosis. Curr Top Med Chem 2013;13(22):2866-84.

21. Ohashi Y, Hirayama A, Ishikawa T, Nakamura S, Shimizu K, Ueno Y, et al. Depiction of metabolome changes in histidine-starved Escherichia coli by CE-TOFMS. Mol Biosyst. 2008;4(2):135-47.

22. Wu H, Tian D, Fan $X$, Fan W, Zhang $Y$, Jiang $S$, et al. Highly efficient production of I-histidine from glucose by metabolically engineered. ACS Synth Biol. 2020;9(7):1813-22.

23. Edwards C, Canfield J, Copes N, Brito A, Rehan M, Lipps D, et al. Mechanisms of amino acid-mediated lifespan extension in Caenorhabditis elegans. BMC Genet. 2015;16:8

24. Zečić A, Dhondt I, Braeckman BP. The nutritional requirements of. Genes Nutr. 2019;14:15.

25. Pabst MJ, Kuhn JC, Somerville RL. Feedback regulation in the anthranilate aggregate from wild type and mutant strains of Escherichia coli. J Biol Chem. 1973;248(3):901-14.

26. van der Goot AT, Zhu W, Vázquez-Manrique RP, Seinstra RI, Dettmer K, Michels $\mathrm{H}$, et al. Delaying aging and the aging-associated decline in protein homeostasis by inhibition of tryptophan degradation. Proc Natl Acad Sci U S A. 2012;109(37):14912-7.

27. Roager HM, Licht TR. Microbial tryptophan catabolites in health and disease. Nat Commun. 2018;9(1):3294.

28. Anyanful A, Dolan-Livengood JM, Lewis T, Sheth S, Dezalia MN, Sherman MA, et al. Paralysis and killing of Caenorhabditis elegans by enteropathogenic Escherichia coli requires the bacterial tryptophanase gene. Mol Microbiol. 2005;57(4):988-1007.

29. Zhao Z, Chen S, Wu D, Wu J, Chen J. Effect of mufti-gene knockout of L-tryptophan transport system on L-tryptophan production in Escherichia coli. Sheng Wu Gong Cheng Xue Bao. 2011;27(12):1765-72.

30. Andrews SC, Robinson AK, Rodríguez-Quiñones F. Bacterial iron homeostasis. FEMS Microbiol Rev. 2003;27(2-3):215-37.

31. Kim Yl, Cho JH, Yoo OJ, Ahnn J. Transcriptional regulation and life-span modulation of cytosolic aconitase and ferritin genes in C. elegans. J Mol Biol. 2004;342(2):421-33.

32. Cabreiro F, Au C, Leung KY, Vergara-Irigaray N, Cochemé HM, Noori T, et al. Metformin retards aging in C. elegans by altering microbial folate and methionine metabolism. Cell. 2013;153(1):228-39.
33. Yung PY, Lo Grasso L, Mohidin AF, Acerbi E, Hinks J, Seviour T, et al. Erratum: global transcriptomic responses of Escherichia coli K-12 to volatile organic compounds. Sci Rep. 2017;7:33108.

34. Yung PY, Grasso LL, Mohidin AF, Acerbi E, Hinks J, Seviour T, et al. Global transcriptomic responses of Escherichia coli K-12 to volatile organic compounds. Sci Rep. 2016;6:19899.

35. Luo W, Pant G, Bhavnasi YK, Blanchard SG, Brouwer C. Pathview Web: user friendly pathway visualization and data integration. Nucleic Acids Res. 2017:45(W1):W501-8

36. Luo W, Brouwer C. Pathview: an R/Bioconductor package for pathway-based data integration and visualization. Bioinformatics. 2013;29(14):1830-1.

37. Kanehisa M, Goto S. KEGG: kyoto encyclopedia of genes and genomes. Nucleic Acids Res. 2000;28(1):27-30.

38. Kanehisa M, Sato Y, Furumichi M, Morishima K, Tanabe M. New approach for understanding genome variations in KEGG. Nucleic Acids Res. 2019;47(D1):D590-5.

39. Kanehisa M. Toward understanding the origin and evolution of cellular organisms. Protein Sci. 2019;28(11):1947-51.

40. Maglott D, Ostell J, Pruitt KD, Tatusova T. Entrez Gene: gene-centered information at NCBI. Nucleic Acids Res. 2005;33(Database issue):D54-8.

41. Keseler IM, Mackie A, Santos-Zavaleta A, Billington R, Bonavides-Martínez C, Caspi R, et al. The EcoCyc database: reflecting new knowledge about Escherichia coli K-12. Nucleic Acids Res. 2017;45(D1):D543-50.

42. Consortium U. UniProt: a worldwide hub of protein knowledge. Nucleic Acids Res. 2019;47(D1):D506-15.

43. McCarthy DJ, Chen Y, Smyth GK. Differential expression analysis of multifactor RNA-Seq experiments with respect to biological variation. Nucleic Acids Res. 2012;40(10):4288-97.

44. Robinson MD, McCarthy DJ, Smyth GK. edgeR: a Bioconductor package for differential expression analysis of digital gene expression data. Bioinformatics. 2010;26(1):139-40.

45. Team RC. R: a language and environment for statistical computing. Vienna: R Foundation for Statistical Computing; 2020.

46. Galili T, O'Callaghan A, Sidi J, Sievert C. heatmaply: an R package for creating interactive cluster heatmaps for online publishing. Bioinformatics. 2018;34(9):1600-2.

47. Huber W, Carey VJ, Gentleman R, Anders S, Carlson M, Carvalho BS, et al. Orchestrating high-throughput genomic analysis with Bioconductor. Nat Methods. 2015;12(2):115-21.

48. Davis S, Meltzer PS. GEOquery: a bridge between the Gene Expression Omnibus (GEO) and BioConductor. Bioinformatics. 2007:23(14):1846-7.

49. Caspi R, Billington R, Fulcher CA, Keseler IM, Kothari A, Krummenacker $M$, et al. The MetaCyc database of metabolic pathways and enzymes. Nucleic Acids Res. 2018;46(D1):D633-9.

50. Dirksen P, Marsh SA, Braker I, Heitland N, Wagner S, Nakad R, et al. The native microbiome of the nematode Caenorhabditis elegans: gateway to a new host-microbiome model. BMC Biol. 2016;14:38.

51. Berg M, Stenuit B, Ho J, Wang A, Parke C, Knight M, et al. Assembly of the Caenorhabditis elegans gut microbiota from diverse soil microbial environments. ISME J. 2016;10(8):1998-2009.

52. Félix MA, Braendle C. The natural history of Caenorhabditis elegans. Curr Biol. 2010;20(22):R965-9.

53. Stuhr NL, Curran SP. Bacterial diets differentially alter lifespan and healthspan trajectories in C. elegans. Commun Biol. 2020;3(1):653.

\section{Publisher's Note}

Springer Nature remains neutral with regard to jurisdictional claims in published maps and institutional affiliations. 